University of Nebraska - Lincoln

DigitalCommons@University of Nebraska - Lincoln

To Improve the Academy

Professional and Organizational Development

Network in Higher Education

1998

Developments in Initial Training and Certification of University

Teachers in the UK: Implications for the US

Graham Gibbs

Follow this and additional works at: https://digitalcommons.unl.edu/podimproveacad

Part of the Higher Education Administration Commons

Gibbs, Graham, "Developments in Initial Training and Certification of University Teachers in the UK: Implications for the US" (1998). To Improve the Academy. 403.

https://digitalcommons.unl.edu/podimproveacad/403

This Article is brought to you for free and open access by the Professional and Organizational Development Network in Higher Education at DigitalCommons@University of Nebraska - Lincoln. It has been accepted for inclusion in To Improve the Academy by an authorized administrator of DigitalCommons@University of Nebraska - Lincoln. 
Gibbs, G. (1998). Developments in initial training and certification of university teachers in the UK: Implications for the US. In M. Kaplan (Ed.), To Improve the Academy, Vol. 17 (pp. 69-84). Stillwater, OK: New Forums Press and the Professional and Organizational Development Network in Higher Education. Key Words: distance education, faculty development programs, higher education environment, innovation, instructional technology, new faculty programs.

\section{Developments in Initial Training and Certification of University Teachers in the UK: Implications for the US}

\section{Graham Gibbs}

Open University, UK

Initial training of university teachers is developing in a different direction in the UK than in the US. It concentrates on tenure-track faculty rather than on TAs, on course design rather than on classroom practice, and is much more extensive. This paper contrasts UK and US faculty development practices and their implications. It describes two recent developments in the UK: the establishment of national certification of university teachers and the development of a national course for new faculty to help institutions meet the requirements of certification. The potential for similar mechanisms operating in the US is explored.

Outside the US, programs for training of new faculty as teachers are developing rapidly. Initial training of faculty is compulsory in Norway (Eckman, 1996; Handal, 1997), is commonly extensive and sophisticated in Australia, and is targeted on unique institutional missions and 
career structures elsewhere, such as in Holland (Keesen et al, 1996). The International Consortium for Educational Development has brought faculty developers from many countries together and common trends have been identified (Gibbs, 1997, 1998). These trends are noticeably different from those in the US, where any mandatory training focuses on TAs rather than on faculty. In the UK a national compulsory certification scheme is about to be introduced, building on a successful voluntary scheme and, in effect, professionalizing teaching in higher education. To help institutions to meet the demands of this new scheme, a nationally operating distance learning course has been developed by the Open University. This paper contrasts the current state of faculty development in the UK with that in the US, describes recent dramatic changes in the UK, and considers the potential implications of these changes for US faculty development.

\section{Initial Training of Higher Education Teachers in the UK}

From a slow and small-scale start in the late 1970s, courses for new teachers in higher education have increased enormously in scale and sophistication over the past decade and are now a national focus of attention, policy, and funding. As in the US, the range of provision is wide and there are also diverse rationales underlying initial training; therefore, the following account of differences with the US involves broad generalizations.

\section{Courses are primarily focussed on new faculty, not on TAs.}

While most higher education institutions in the UK have graduate students and the majority have $\mathrm{PhD}$ programs, there are far fewer graduate students than in the US, and they are much more thinly spread across institutions. This means that most teaching is still undertaken by tenure-track faculty. However, this is changing: tenure is becoming less common, adjunct faculty positions are proliferating, and TAs are contributing to teaching to a greater extent and in more institutions. Quality concerns have been identified with both the use of TAs and the use of adjunct faculty (Higher Education Quality Council, 1994). Courses targeting 
these groups of teachers are becoming much more common, and a national investment to upgrade courses for such teachers is beginning. For example, the Fund for the Development of Teaching and Learning (http://chep.open.ac.uk/chep/fdtl) funds a project concerned with the training of new Sociology teachers in 50 institutions (http://chep.open.ac.uk/chep/SocTeach). Despite these changes, the bulk of initial training continues to target quite explicitly new tenure-track faculty, as part of a long term institutional investment in the quality of teaching for the future. This has a number of consequences.

2. Courses are much more extensive than in the US.

It would be expensive for institutions to invest heavily in extended courses for TAs who have limited teaching responsibilities and will most likely be teaching or employed elsewhere in a year or two. But investment in extended courses for faculty is practical if the faculty stay for many years in the same institution, especially as the numbers involved each year are much lower. In the UK the average course is probably now about 200 hours, with the longest about 500 hours and the shortest about 50 hours. Participation in these courses varies but rarely exceeds 40 per year (equivalent to $5 \%$ of total faculty numbers of 800 ). Many courses lead to qualifications such as Postgraduate Certificates in Teaching in Higher Education, validated through Education departments but run out of faculty development centers. It is becoming more common for such Certificates to lead on to Diplomas, Masters, and even $\mathrm{PhD}$ courses as more experienced teachers move forward into departmental and institutional leadership positions.

Once such a course is implemented, it requires special funding and policy decisions to ensure success. It is becoming more common for departments to receive funds to replace faculty time spent on the course and for duties of new faculty to be lightened to allow participation in the course. Teaching replacement costs may even exceed the cost of mounting the course. Oxford Brooks University, for example, used to mention its extensive training course in its advertisements for positions in order to attract good faculty. It is my impression that attitudes have changed rapidly 
and that senior faculty are commonly out of touch with the teaching-oriented values of new, young faculty.

\section{Courses are linked to personnel decisions more than in the} US.

It is common for initial training courses to be compulsory for all faculty without equivalent qualifications or without three years of full-time teaching experience. It is becoming more common for successful completion of courses to be a condition of tenure. This has led to department chairs taking teaching support for their new faculty much more seriously. In many courses it is possible to fail, and failure can be based on evidence from observed teaching sessions included in portfolios of evidence of competence. There are now cases of excellent researchers who are unable to provide evidence of competence as teachers and who were, therefore, refused tenure. Even the London School of Economics, which is in other respects copying tough US tenure arrangements, has included successful completion of its teaching program in its tenure procedures.

4. The content and process of courses is oriented toward course design, reflective practice, and innovation rather than classroom skills.

The content of these courses in the UK is noticeably different from that in the US and reflects the needs of those in the courses and the priorities of institutions. Most new faculty in the UK have several years of part-time or hourly paid teaching experience prior to their appointment and have quite extensive teaching responsibilities from the start. They are not teaching courses designed by others but need to design their own courses. They also need to know about the design and management of examination and assessment systems, about evaluation and improvement of courses, about building the development of transferable skills into the curriculum, and so on. Institutions may not want some of the existing traditional teaching and learning patterns reproduced because they are not able to cope with the challenges posed by increased student numbers, the declining funding levels per student, the diversity of students, or with the integration of instructional technology. Institutions need their new faculty to bring 
about change. Courses, therefore, pay much less attention than in the US to details of conventional classroom skills and much more attention to course design and change processes. Many courses are explicitly underpinned with Schon's model of reflective practice and typically involve action research projects rather than micro-teaching. Desired outcomes of courses have shifted towards the ability to diagnose problems and introduce appropriate new solutions and away from how to use traditional classroom and teacher-centered methods with fine-tuned skill. This shift has been very successful in institutions that have had such courses in place for a decade. It is the experience of those running such courses that faculty who have been trained in this way often become change agents in their departments and lead innovations within five to eight years.

There may be insufficient emphasis on skill in these courses for new faculty. However, this potential problem is now being examined in the UK as new introductory courses are being developed for TAs that concentrate on much the same areas as TA training in the US. In contrast, it is difficult to see where change in higher education is going to come from in the US. Much of its current preparation for teaching seems designed to reproduce or fine-tune existing patterns and comes to an end before faculty have any significant responsibility for design, review, or change. There are clearly exceptions to this pattern, and in some institutions even TAs have extensive responsibilities and their training as teachers reflects the scope they have for decision-making. However, US institutions cannot be at all confident that their new tenure-track faculty have had any training in course design whatsoever.

A consequence of the "reflective practice" rationales of courses in the UK is that of the $\mathbf{2 0 0}$ or so hours a course might last, only half may be in workshops (for example, half a day a week for a year), and the other half may involve concurrent teaching practice-but planned for, executed, and de-briefed much more thoroughly than might otherwise be the case. 


\section{The Development of Voluntary Certification: The SEDA Scheme}

SEDA is the Staff and Educational Development Association, the nearest UK equivalent to POD in the US. In 1991 SEDA tried to do what HERDSA in Australia had attempted-to define what they meant by good teaching. They ended up with a specification for minimum competence that provided a blueprint for initial training: a definition of learning outcomes of a course for new teachers. This blueprint did not specify the content, process, or length of a course, but only its outcomes. These outcomes proved surprisingly uncontentious:

SEDA Outcomes (couched in American terminology)

- designed a course of study

- used a wide and appropriate range of teaching methods effectively

- provided support to students on academic and personal issues in a way acceptable to a wide range of students

- used a wide and appropriate range of evaluation techniques to support student learning and record achievement

- reviewed their own work with a range of self, peer, and student monitoring and evaluation techniques

- performed effectively service and academic administrative tasks

- developed personal and professional coping strategies

- reflected on their practice, assessed their development needs, and planned their own continuing professional development

In addition, and more controversially, institutions also had to demonstrate to SEDA how their courses were grounded in the following principles and values.

\section{SEDA Principles and Values}

- understanding how students learn

- concern for student development

- scholarship in subject and in teaching

- collegiality

- equality of opportunity 


\section{- reflection on practice}

While other professions, such as medicine and law, have explicit professional values, and academics claim to have values, the idea of specifying values for the academic profession has proved challenging.

A "certification" scheme was developed in which SEDA would accredit courses that could demonstrate that they achieved the SEDA outcomes in a way grounded in the SEDA values. Faculty who successfully completed such courses would become SEDA Accredited Teachers. The institutions run their own courses and assess their own teachers, but, if their course has been accredited by SEDA, then their teachers gain "Accredited Teacher" status. In this way institutional autonomy is respected and a great diversity of courses has been allowed to flourish, but all producing at least the SEDA-specified outcomes.

At the start it was not known if anyone would take such a voluntary scheme seriously. What happened exceeded all expectations and the ability of SEDA to keep up with demand for accreditation visits. By $1998,30 \%$ of UK institutions are running SEDA accredited courses and nearly $20 \%$ more are in the process of gaining accreditation. This was achieved with no funding from the government or from a special initiative: institutions themselves pay a modest fee to SEDA that covers their administrative and consultancy costs.

Even well-established courses have re-oriented their focus and changed their assessment so as to meet SEDA requirements. Many new courses have been developed, and many new faculty development posts have been created to teach them. There has been an enormous increase in the average size and level of sophistication of courses as a direct consequence of this new "benchmark" against which they could be tested. Institutions could tell, for the first time, whether their own initial training provision was well behind what might reasonably be expected. Outside the UK, courses used this "benchmarking" process explicitly in order to establish the international comparability of their courses (Weeks, 1996), and a number of universities in Australia and South East Asia are currently SEDA accredited. A cut-down version of this scheme, aimed at TAs and adjunct faculty (the SEDA Associate Teacher Scheme) has been developed and implemented, as well as 
schemes for academic-related staff who teach students (such as librarians and computer center staff) and for faculty and instructional development staff (the SEDA Fellowship Scheme). Currently, research funding councils are collaborating to develop an accreditation scheme for $\mathrm{PhD}$ supervisors, as a way to improve $\mathrm{PhD}$ completion rates. For a fuller account of the development of the SEDA Accreditation Schemes see Baume and Baume (1997) and the SEDA website (http://www.seda.demon.co.uk).

The normal assessment process for courses achieving SEDA Accreditation is that of a portfolio of evidence of teaching assessed against explicit criteria based on the SEDA outcomes and values. Teaching portfolios had become widely used as developmental tools and for promotion purposes, and now they are also being used for accreditation.

\section{National Policy Changes Concerning Initial Training}

In 1996 a National Commission of Enquiry reviewed UK higher education. Amongst its many activities the Commission sought evidence from SEDA. Its final report, published in 1997, recommended that there should be compulsory accreditation of higher education teachers and a National Institute for Learning and Teaching in Higher Education established to oversee the professionalization of teaching in higher education throughout the UK. New teachers should be expected to become "Associate Members" of this Institute and experienced teachers would be encouraged to become "Members." In time this Institute would become self-funded, based on membership fees. The Institute would coordinate developments in teaching and learning, fund research into teaching and learning, and support the development of uses of instructional technology. Subsequent working groups to plan accreditation and to establish the Institute have brought vicechancellors, and other interest groups on board. Interestingly there has been strong support from the teaching unions, who see this as a way of protecting faculty from replacement by cheap, poorly qualified, casual teaching labor. Students' organizations have been wholeheartedly in favor. Industry and commerce have never understood why 
higher education did not train its workforce properly, and its view has been "and about time too." Throughout negotiations, the SEDA model has been retained in large part, despite strong and sometimes heated controversy involving some research universities and agencies with other agendas. The Institute will be established by late 1998, and accreditation will be established by the following year, subject to reactions by universities to a national consultation document early in 1998. Membership of the Institute is currently planned to be in four categories:

Associate Membership Part I:

Associate Membership Part II:

Membership:

Fellowship:
For TAs and adjunct faculty, focusing on classroom teaching and marking, and as a first stage for faculty.

For faculty, focusing on course design and development.

For senior faculty, focusing on program development.

Focusing on leadership of change in teaching and learning, involving curricula change within a discipline, or pedagogic research.

Prior to the publication of the National Commission of Enquiry's report, the Higher Education Funding Council for England (HEFCE), the body that funds higher education, commissioned work to develop a strategy for improving teaching and learning in UK higher education in a coherent way, to replace previous isolated initiatives. The report (Gibbs, 1997) argued that institutions could be leveraged through changes in funding mechanisms to develop and implement their own teaching and learning strategies in a way that balanced concerns for teaching and research. It also recommended funding to meet the enormously increased demands that accreditation would bring. In November 1997, a new National Teaching and Learning Policy was announced by the HEFCE that supported accreditation and the implementation of institutional teaching and learning strategies, encompassing arrangements to meet accreditation requirements.

While details of implementation are yet to be agreed upon and the political fall-out has yet to be resolved, it is clear that by 1999 there 
will be a strong requirement, or financial leverage, on institutions to implement accreditation in a comprehensive way.

\section{Development of a National Course of Initial Training to Meet Certification Demands}

Despite the optimistic account given above of the shape of initial training of teachers in higher education in the UK, there are still institutions with limited or no provision and others, such as small technical training institutes, music conservatories, and the like, which are in a poor position to develop their own courses. There are also adjunct faculty and other categories of teachers without access to training or accreditation. Early evidence from pilot schemes suggests that there is a large latent demand from experienced faculty to gain accreditation retrospectively, on the basis of competence developed through experience. There is currently no way to meet this demand. In addition, many existing courses are run from very small faculty development units with limited capacity to expand their activities. They often face large and sudden variations in the number of new faculty they have in their courses, due to financially induced changes in recruitment, and they cannot afford to maintain substantial courses when numbers drop. There is an acute shortage of competent and experienced faculty development and instructional development staff. There is no organized training for such staff, and several recent, nationally advertised faculty development positions have not attracted sufficiently strong fields to allow appointment. Faculty development has expanded rapidly, but it is not able to cope with the increased demands that accreditation will make. For all these reasons there is a national need for institutions and individual teachers to be able to get access to flexible forms of initial training that can substitute, complement, or supplement an institution's own in-house provision.

In anticipation of this, in 1997, a new Centre for Higher Education Practice was established at the Open University to develop distance learning courses that institutions and individual teachers could purchase so as to meet accreditation requirements. The Open University has production and delivery systems capable of supporting complex courses with very large student numbers world-wide: it currently has 
200,000 undergraduate and graduate students. For example, it already trains new schoolteachers with distance support for in-service training with a local mentor, based in literally thousands of schools. The Centre for Higher Education Practice was founded by Graham Gibbs, who had established the Oxford Centre for Staff Development as a largescale provider of academic training workshops, and David Baume, who was the architect of the SEDA accreditation scheme. Courses are targeted directly at the new Institute categories of membership, with the first course, aimed at Association Membership Part I, starting in the academic year 1998/9.

The courses are designed to allow the maximum possible flexibility of usage by institutions, which are likely to be the main clients, and by individual teachers. The components are an assessment framework, a set of materials, and a course with discipline-specific tutor groups of 20 new teachers. Optional support includes a local mentor and regionally organized, one-day training workshops on the topics covered in the manuals and on how to prepare a portfolio for accreditation. These components are illustrated in Figure 1.

The main advantages over current in-house provision are:

1. The quality of support materials is very much higher than individual institutions can manage to provide. Because of the scale of its operation (the Open University envisages about 5,000 teachers enrolled within four years) many person-years of writing time and other resources can be allocated to materials development, and Open University course production standards are very high. Technical support for large scale use of, for example, computer tuition and conferencing, is also readily available.

2. Discipline-specific tuition and support material is possible. Tutors will be SEDA-accredited and from the same discipline as the teachers they are tutoring. Oxford Brookes University used to have a new chemist about every five years and there was no possibility of anything other than a generic course. At the Open University we will be able to give new chemistry teachers their own chemistry group and chemistry tutor every year.

3. Scheduling will be flexible, coping with new faculty arriving at times other than September and allowing submission of a portfolio at any of a number of points over the first two years. 
FIGURE 1: Structure of Open University Courses for Teachers

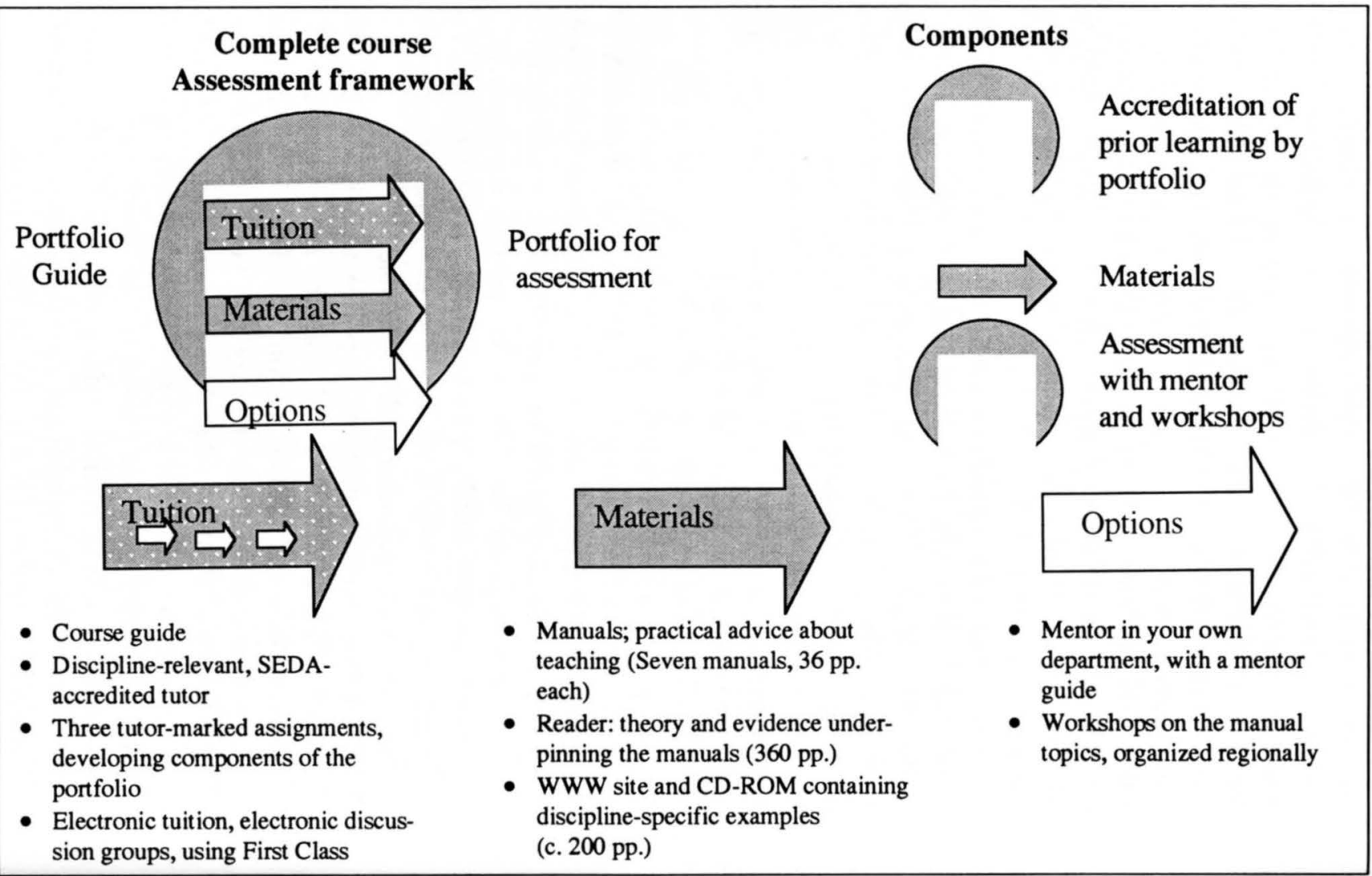


4. The framework can easily accommodate experienced faculty who want to present a portfolio for accreditation but not take a course alongside new faculty.

These components can be used in any combination. For example, an institution could:

1. run its own workshop program for its new faculty but use the Open University assessment framework so as not to have to seek accreditation itself;

2. use the entire Open University package but provide a departmentbased mentor in support;

3. run its own department-based program and its own institutionwide assessment framework but use the Open University's materials;

4. run its own course for new faculty but use the Open University for its adjunct faculty and for experienced faculty;

5. fund individual teachers of whatever category to make whatever use they wanted of Open University provision and make neither policy nor practical provision.

The first level Open University course, Teaching in Higher Education, will be suitable for TAs and the second, Course Design in Higher Education, for new faculty. Together they lead to a Postgraduate Certificate in Teaching in Higher Education. In line with other practice in the UK, these courses are 250 hours each, about half of which involves concurrent teaching practice and half additional work associated with the materials and developing a portfolio. Subsequent Master's level courses will be designed to support teachers in achieving full membership in the Institute. A pilot course will operate with about 350 student in $1998 / 9$, and a $\$ 400,000$ national project to support new teachers in Sociology will use the Open University course in the same year. Full operation, plus international piloting, will start in 1999/2000. The University of Cambridge will be using the Open University courses in 1998/9. 


\section{Implications and Possibilities for the US}

Control of higher education in the UK and the US is so different that few parallels can be drawn between the systems. The US has state higher education systems, a private sector, and no national sector. In the UK, all but one of its institutions is controlled and funded indirectly by national government. However, there are several elements of similarity that suggest potential applications of UK developments in the US.

1. Some state university and college systems in the US are the size of the entire higher education system in England, and many are the size of higher education in Scotland or Wales. Some of these are run with a similar degree of control, in terms of funding and policy, to the national system in the UK. It is not hard to imagine such state systems wanting to develop their own approach to certification of their faculty in order to upgrade current training and to encourage the kinds of innovation in teaching methods necessary to cope with the funding and diversity issues state systems face. If a state wanted a "market advantage" this might be a way to achieve it at very modest cost.

2. The SEDA Scheme in the UK has developed with entirely voluntary involvement of institutions, and with no government or agency funding, until it included $50 \%$ of the sector within seven years of its launch. Even without the recent support of national policy or funding, it would probably have continued to develop until it encompassed all but the research elite and the idiosyncratic. It is easy to imagine an organization or association in the US, such as POD or AAHE, developing a voluntary certification scheme of a similar kind and supporting its voluntary adoption. This might involve a period of consultation and development of a US-appropriate scheme, its voluntary prototyping in several diverse institutions, and then a national-scale project supporting wider adoption in a pattern familiar to AAHE initiatives. Participation would probably be lower than in the UK for a variety of reasonsbut then the take-up of other national scale initiatives in the US has been patchy but still very worthwhile. 
3. Some institutions might want to adopt a rigorous accreditation scheme of this kind for their own distinct purposes - for example, the University of Phoenix or the U.S. Air Force Academy.

4. Any certification scheme in the US would require nothing short of a revolution in the scale and sophistication of support for the development of faculty, given the current low levels of support and small scale of operation in most institutions. Any rapid increase in scale of such support would probably require an initiative of its own to support faculty development centers with materials assessment frameworks, workshops, training for the faculty developers, and so on. There are some very good support materials provided by some universities, aimed at TAs, but most are brief, mixed in quality, and patchy in coverage. Support for the teaching of individual disciplines is very patchy indeed, despite the models provided by the American Sociological Association and a few others. There is plenty of scope for a national initiative to develop support materials for institutions for their own in-house courses and to raise standards above those of a cottage industry.

5. Finally, there would seem to be a marketing opportunity for an institution capable of mounting a distance learning course on the scale of the Open University in the UK. There could be a substantial demand for such a course, especially if it was offered in a modular format capable of meshing with elements of in-house provision, as in the UK. Alternatives for mounting such a course include a consortium of institutions pooling resources, a large specialist distance learning organization, or a well-placed individual institution in collaboration with the Open University. The Open University, UK, is currently seeking regional accreditation in the US to operate as the Open University of America.

\section{References}

Baume, C., \& Baume, D. (1997). A national scheme to accredit university teachers. International Journal for Academic Development, 2, 1.

Eckman, B. (1996). Compulsory pedagogic training as a requirement for an Associate Professorship. International Consortium for Educational Development Conference: Preparing University Teachers. Vasa, Finland. 
Gibbs, G. (1997). Preparing university teachers: An international overview of practice. Proceedings of the 21st International Improving University Teaching Conference. Nottingham, UK.

Gibbs, G. (1997). A teaching and learning strategy for higher education. Bristol: Higher Education Funding Council for England.

Gibbs, G. (in press). The preparation of university teachers in Europe and Australasia. In J. Forrest-Campion (Ed.), University teaching: International perspectives. Boston: Brock.

Handal, G. (1997). Compulsory initial training of university teachers in Norway. Committee of Vice Chancellors and Principals/Society for Research into Higher Education Conference: Training Teachers in Higher Education, London.

Keesen, F., Wubbels, T., Tartwijk, J. V., \& Bouhuijs, P. A. J. (1996). Preparing university teachers in the Netherlands: Issues and trends. International Journal of Academic Development, 1(2), 8-16.

Higher Education Quality Council. (1994). Learning from audit. London: Higher Education Qulaity Council.

Weeks, P. (1996). Preparing university teachers in Australia: Benchmarking best practice. International Consortium for Educational Development in Higher Education Conference: Preparing University Teachers. Vasa, Finland.

\section{Contact:}

Graham Gibbs

Centre for Higher Education Practice

Open University

Milton Keynes MK7 6AA

UK

441908858439

441908858438 FAX

g.p.gibbs@open.ac.uk

Graham Gibbs is Co-Director of the Centre for Higher Education Practice at the Open University in the UK. He has been involved with training new faculty since 1980 and his Centre operates a distance leaming program for new faculty at other universities, including Cambridge. He is the founder of the Intemational Consortium for Educational Development in Higher Education and the author of many books and articles about teaching and learning in higher education. 